\title{
Diagnostic Value and Prognostic Significance of Pleural C-Reactive Protein in Lung Cancer Patients with Malignant Pleural Effusions
}

\author{
Do-Sim Park, ${ }^{1 *}$ Dong Kim ${ }^{2 *}$ Ki-Eun Hwang, ${ }^{2}$ Yu-Ri Hwang, ${ }^{2}$ Chul Park, ${ }^{2}$ Chang-Hwan Seol, ${ }^{2}$ \\ Kyung-Hwa Cho, ${ }^{2}$ Byoung-Ryun Kim, ${ }^{3}$ Seong-Hoon Park, ${ }^{4}$ Eun-Taik Jeong, ${ }^{2}$ and Hak-Ryul Kim ${ }^{2}$ \\ Departments of 'Laboratory Medicine, Internal Medicine, Institute of Wonkwang Medical Science, \\ ${ }^{3}$ Departments of Obstetrics \& Gynecology, and ${ }^{R}$ Radiology, Wonkwang University School of Medicine, Iksan, Korea.
}

Received: April 25, 2012

Revised: May 25, 2012

Accepted: June 1, 2012

Corresponding author: Dr. Hak-Ryul Kim,

Department of Internal Medicine,

Institute of Wonkwang Medical Science,

Wonkwang University School of Medicine, 895 Muwang-ro, Iksan 570-749, Korea.

Tel: 82-63-859-2583, Fax: 82-63-855-2025

E-mail: kshryj@wonkwang.ac.kr

*Do-Sim Park and Dong Kim contributed equally to this work.

- The authors have no financial conflicts of interest.

Purpose: C-reactive protein (CRP) has been implicated in various inflammatory and advanced malignant states. Increased serum CRP (s-CRP) levels have been shown to be associated with independent prognostic factors for survival in patients with advanced lung cancer. However, only few studies have focused on the role of CRP in pleural effusions. This study aimed to evaluate the diagnostic and prognostic value of pleural CRP (p-CRP) in lung cancer patients with malignant pleural effusion (MPE). Materials and Methods: Pleural effusion (PE) samples were collected from patients with MPE (68 lung cancers; 12 extrathoracic tumors), and from 68 patients with various benign conditions ( 31 with pneumonia; 37 with tuberculosis). Concentrations of $\mathrm{p}$ - and s-CRP were measured by enzyme-linked immunosorbent assay. CRP level in pleural fluid and its association with survival were examined. Results: $\mathrm{p}$-CRP levels correlated with s-CRP levels $(\mathrm{r}=0.82, p<0.0001)$. For the differential diagnosis of MPE and benign PE, the area under the receiver operating characteristic curve was greater for $\mathrm{p}-\mathrm{CRP}(0.86)$ than for s-CRP $(0.77)$. High $\mathrm{p}$-CRP expression significantly correlated with shorter overall survival $(p=0.006)$. P-CRP was independent prognostic factor significantly associated with overall survival on multivariated analysis $(p=0.0001)$. The relative risk of death for lung cancer patients with high p-CRP levels was 3.909 (95\% confidence interval, 2.000-7.639). Conclusion: P-CRP is superior to s-CRP in determining pleural fluid etiology. Quantitative measurement of p-CRP might be a useful complementary diagnostic and prognostic test for lung cancer patients with MPE.

Key Words: Pleural CRP, diagnosis, prognosis, lung cancer, pleural effusion

\section{INTRODUCTION}

\section{(C) Copyright:}

Yonsei University College of Medicine 2013

This is an Open Access article distributed under the terms of the Creative Commons Attribution NonCommercial License (http://creativecommons.org/ licenses/by-nc/3.0) which permits unrestricted noncommercial use, distribution, and reproduction in any medium, provided the original work is properly cited.
Malignant pleural effusion (MPE) is a common and distressing condition seen at the advanced stage of lung cancer. Approximately $50 \%$ of lung cancer patients develop pleural effusions at a later stage of the disease. ${ }^{1}$ The presence of MPE usually indicates the severity of illness and a short survival time. ${ }^{2}$ In order to improve patient outcomes, advances in the identification of proteins and molecular pathways that affect key proliferation and survival mechanisms are needed. However, few cellular 
proteins have been identified whose altered regulation correlates with prognosis in lung cancer patients with MPE.

The conventional cytological examination of pleural fluids for differentiating benign pleural effusion (PE) from MPE is of limited diagnostic accuracy. ${ }^{3}$ Accordingly, a large number of biochemical markers in pleural fluid have been intensively evaluated to improve the diagnosis of MPE. . $^{4-7}$ However, the sensitivity of these tests has so far failed to give acceptable results in almost all these series. It is thus necessary to identify more reliable and easily used biomarkers that may enhance MPE diagnosis. ${ }^{8}$ The prognostic value of serum tumor markers has been the subject of a number of publications. ${ }^{9}$ Although tumor markers can also be measured in a readily available body fluid such as serum or urine, their prognostic potential for survival in MPE samples are essentially unknown.

A causal relationship between inflammation and cancer has been described. Persistent infection induces chronic inflammation, and inflammatory cells induce DNA damage in proliferating cell, by generating reactive oxygen and nitrogen species. ${ }^{10}$ Moreover, it has been amply demonstrated that pro-inflammtory cytokines promote tumor growth and metastasis by altering tumor cell biology and activating stromal cells in the tumor microenvironment. ${ }^{11,12} \mathrm{C}$-reactive protein (CRP) was discovered in 1930 and is widely used as a sensitive, but nonspecific, marker of systemic inflammation. $^{13,14}$ Increased serum CRP (s-CRP) levels have been reported in many pulmonary disorders, including pneumonia, malignancies, and pulmonary thromboembolism. ${ }^{15,16}$ However, the role of CRP in pleural effusions is still unclear. ${ }^{17,18}$ In patients with non-small cell lung cancer (NSCLC), multiple myeloma, renal cell carcinoma, prostate cancer, ovarian cancer, gastrointestinal cancer, and hepatocellular carcinoma, elevated CRP levels prior to therapy have been shown to have an adverse impact on prognosis. ${ }^{19-24}$ Surprisingly, however, no studies have analyzed pleural CRP (p-CRP) as a prognostic factor in advanced NSCLC.

In this study, we aimed to investigate the diagnostic and prognostic power of quantitative $\mathrm{p}-\mathrm{CRP}$ expression, as compared to s-CRP, in lung cancer patients with MPE.

\section{MATERIALS AND METHODS}

\section{Patient selection}

A total of 323 consecutive patients who presented with pleural exudative effusion were enrolled in the study between
January 2009 and July 2011 from the Department of Pulmonology, Wonkwang University Hospital. Effusions were classified as transudates or exudates using Light's criteria, ${ }^{25}$ and patients with transudates, such as those with heart failure, liver cirrhosis, or nephrotic syndrome, were excluded. Effusions were obtained from 80 patients with MPE (49 with adenocarcinoma of the lung, 19 with non-adenocarcinoma of the lung, and 12 with other primary sites of malignancy), 31 with parapneumonic $\mathrm{PE}$, and 37 with tuberculous PE. According to their final diagnoses, the 148 eligible participants were classified into 2 groups: MPE $(n=80)$ or benign PE $(n=68)$. The determination of the etiology of pleural effusions was based on widely accepted criteria, as previously described. ${ }^{26}$ The survival time in patients with MPE was measured from the time of diagnosis to the date of death. This study protocol was approved by the Institutional Review Board for Human Studies at the Clinical Research Center of Wonkwang University Hospital. All of the recruited patients and volunteers provided written informed consent.

\section{Tumor marker assays}

Blood and PE samples were collected within $24 \mathrm{~h}$ of admission or on a symptomatic day before treatment, and centrifuged immediately at $4^{\circ} \mathrm{C}$. Cell-free supernatants were collected as aliquots and stored at $-80^{\circ} \mathrm{C}$ until analysis. CRP was analyzed by routine clinical laboratory test protocols using an automated chemical analyzer (Modular P800; Roche Diagnostics GmbH, Mannheim, Germany).

\section{Statistical analyses}

All statistical analyses of differences between MPE and benign PE were performed using the Mann-Whitney U test. Spearman correlations were used to determine the relationships between $\mathrm{p}$ - and s-CRP. The diagnostic accuracies of $\mathrm{p}$ - and s-CRP in discriminating between lung cancer with MPE and benign PE were compared by constructing receiver operating characteristic (ROC) curves. The optimum cut-off point from the ROC analysis was established by selecting the value that provides the greatest sum of sensitivity and specificity. Survival analyses were performed using the Kaplan-Meier method, and significant differences in survival rates were compared using the log-rank test. The Cox proportional hazard regression model was used to compare the relative influences of different prognostic factors. Data were analyzed using SPSS software version 15 (SPSS Inc., Chicago, IL, USA) and MedCalc version 11.5 (MedCalc software, Mariakerke, Belgium). Statistical significance 
was defined as $p<0.05$.

\section{RESULTS}

The demographic characteristics of the study subjects are presented in Table 1. There were no significant differences in gender, pleural glucose levels, and pleural lactate dehydrogenase (LDH) levels between MPE and benign PE patients. However, age and pleural $\mathrm{pH}$ were significantly higher and pleural white blood counts (WBC), protein, protein Light's ratio and LDH Light's ratio were significantly lower in MPE patients. Fig. 1 shows significantly positive correlation between $\mathrm{p}$ - and $\mathrm{s}$-CRP levels $(\mathrm{r}=0.82, p<0.0001)$, indicating a relationship between $\mathrm{p}$ - and s-CRP.

\section{Diagnostic value of $\mathrm{p}-\mathrm{CRP}$}

As seen in Fig. 2, concentrations of p-CRP were signifi- cantly lower than those of s-CRP $(p<0.0001)$. Further, pCRP levels were significantly lower in MPE than in benign PE $(p<0.0001)$.

To evaluate whether $\mathrm{p}$ - and s-CRP levels could discriminate between MPE and benign PE, cut-off points were determined by the maximum sum of sensitivity and specificity. We used cut-off points of $25 \mathrm{mg} / \mathrm{L}$ and $82 \mathrm{mg} / \mathrm{L}$ for pand s-CRP, respectively, yielding sensitivity and specificity values of $72 \%$ and $83 \%$ for $\mathrm{p}$-CRP, and $63 \%$ and $73 \%$ for s-CRP, respectively. Additionally, p-CRP exhibited elevated diagnostic sensitivity (87\%) in lung cancer patients with MPE. The ROC curves of $\mathrm{p}$ - and s-CRP for distinguishing lung cancer with MPE from benign PE are shown in Fig. 3. We found that the AUC of ROC curves (diagnostic accuracy) of p-CRP (0.86) was superior to that of s-CRP $(0.77)$.

\section{Prognostic implications of $\mathrm{p}-\mathrm{CRP}$}

We next examined whether the expression status of p-CRP

Table 1. Demographic and Laboratory Characteristics of the Study Population

\begin{tabular}{lccc}
\hline Variables & $\begin{array}{c}\text { Malignant PE }(\mathrm{n}=80) \\
\text { Mean } \pm \text { SD }\end{array}$ & $\begin{array}{c}\text { Benign } \mathrm{PE}(\mathrm{n}=68) \\
\text { Mean } \pm \text { SD }\end{array}$ & $p$ value \\
\hline Age, yrs (range) & $68.3 \pm 15.0$ & $60.1 \pm 18.1$ & 0.003 \\
Sex, male/female, $\mathrm{n}$ & $53 / 27$ & $48 / 20$ & NS \\
\hline Pleural fluid & & & 0.01 \\
\hline $\mathrm{pH}$ & $7.44 \pm 0.51$ & $7.19 \pm 0.50$ & 0.03 \\
WBC, $/ \mathrm{mL}$ & $2066.9 \pm 3918$ & $3278.1 \pm 2875$ & $\mathrm{NS}$ \\
\hline Glucose, $\mathrm{mg} / \mathrm{dL}$ & $118.8 \pm 55.1$ & $108.6 \pm 69.0$ & 0.007 \\
\hline Protein, g/dL & $4.35 \pm 0.98$ & $4.75 \pm 1.14$ & 0.005 \\
\hline Protein PF/serum ratio & $0.64 \pm 0.13$ & $0.73 \pm 0.13$ & $\mathrm{NS}$ \\
\hline LDH, IU/L & $823.6 \pm 923.5$ & $1033.6 \pm 903.5$ & 0.002 \\
\hline LDH PF/serum ratio & $1.39 \pm 0.90$ & $2.11 \pm 1.44$ & \\
\hline
\end{tabular}

PE, pleural effusions; PF, pleural fluid; LDH, lactate dehydrogenase; WBC, white blood counts.

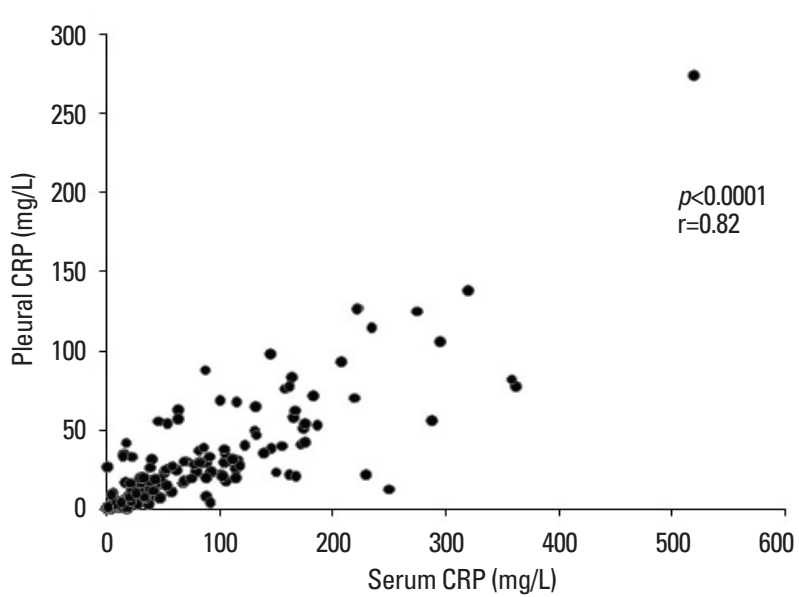

Fig. 1. Correlation between $p$ - and $s-C R P$ in $P E ; r$ is the Spearman coefficient of correlation. CRP, C-reactive protein; PE, pleural effusion; $p$-CRP, pleural CRP; s-CRP, serum CRP.

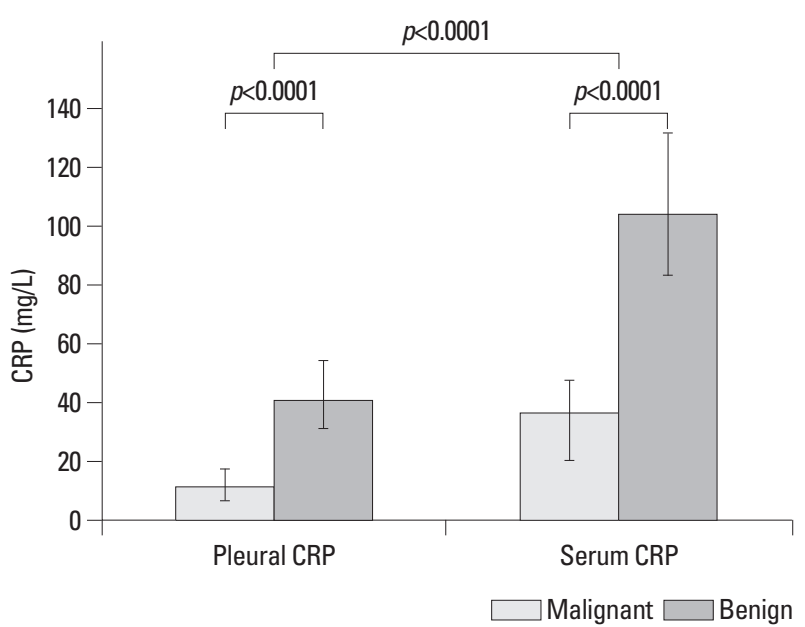

Fig. 2. Comparison of $p-C R P$ vs. s-CRP levels in MPE and benign PE. CRP, $\mathrm{C}$-reactive protein; MPE, malignant pleural effusion; $\mathrm{PE}$, pleural effusion; $\mathrm{p}$ CRP, pleural CRP; s-CRP, serum CRP. 


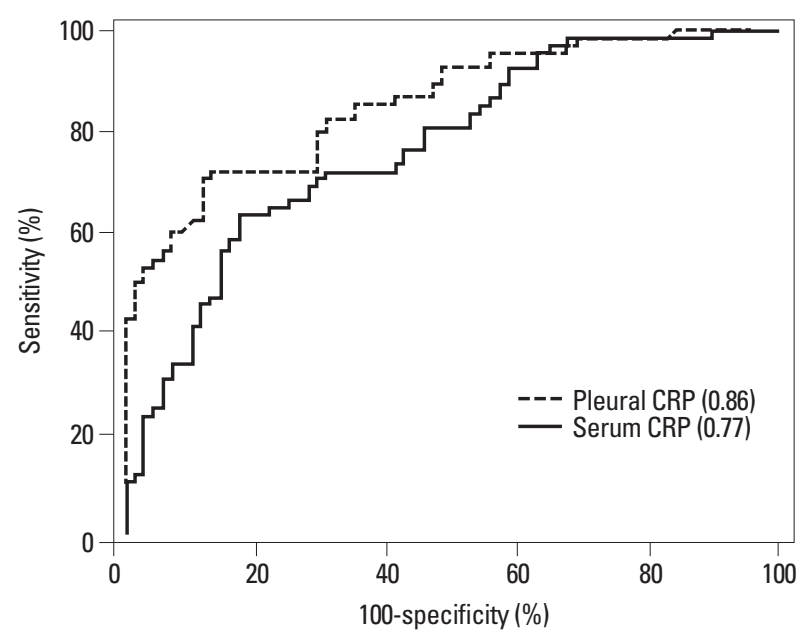

Fig. 3. Comparison of diagnostic accuracies of p-CRP vs. s-CRP in distinguishing lung cancer with MPE from benign $\mathrm{PE}$, using receiver operating characteristic (ROC) curves. The numbers in parentheses indicate the diagnostic accuracies (area under the ROC curve). CRP, C-reactive protein; MPE, malignant pleural effusion; PE, pleural effusion; p-CRP, pleural CRP; sCRP, serum CRP.

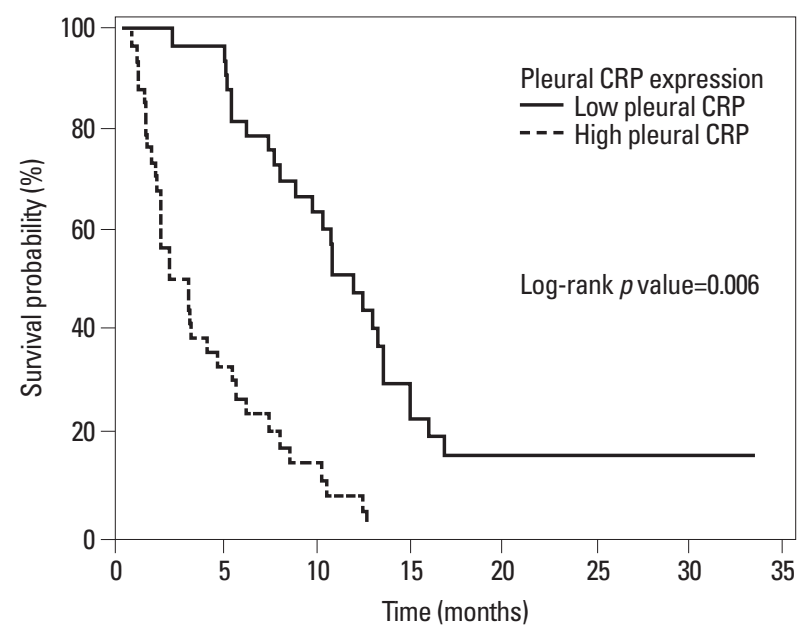

Fig. 4. Overall survival differences between lung cancer with MPE in high and low p-CRP expression, as determined using Kaplan-Meier survival analysis. Patients in the high $\mathrm{p}$-CRP expression group showed reduced overall survival. The $p$ value was obtained from a log-rank test of the difference. CRP, C-reactive protein; MPE, malignant pleural effusion; p-CRP, pleural CRP.

Table 2. Univariate Analysis for Overall Survival in Lung Cancer with MPE

\begin{tabular}{|c|c|c|c|}
\hline Parameters & No. of patients & Overall survival, median $(95 \% \mathrm{CI})$ & $p$ value \\
\hline Age & & & 0.011 \\
\hline$<65$ yrs & 20 & $9.7(7.6-12.9)$ & \\
\hline$>65 \mathrm{yrs}$ & 48 & $5.1(2.8-7.5)$ & \\
\hline Sex & & & NS \\
\hline Female & 22 & $11.3(5.3-15.0)$ & \\
\hline Male & 46 & $5.3(3.1-7.8)$ & \\
\hline Performance status & & & NS \\
\hline $0-2$ & 47 & $8.4(5.7-10.7)$ & \\
\hline $3-4$ & 19 & $1.7(1.1-5.1)$ & \\
\hline Tumor type & & & NS \\
\hline Adenocarcinoma & 49 & $8.4(5.4-11.0)$ & \\
\hline Non-adenocarcinoma & 17 & $5.1(1.9-5.8)$ & \\
\hline Clinical stage & & & NS \\
\hline M1a & 26 & $7.7(5.4-10.7)$ & \\
\hline M1b & 40 & $5.1(1.6-9.3)$ & \\
\hline S-CRP expression & & & NS \\
\hline Low & 31 & $11.8(8.2-13.3)$ & \\
\hline High & 37 & $3.1(1.6-5.2)$ & \\
\hline P-CRP expression & & & 0.006 \\
\hline Low & 34 & $11.0(8.3-13.0)$ & \\
\hline High & 34 & $2.6(1.5-4.7)$ & \\
\hline
\end{tabular}

MPE, malignant pleural effusion; CRP, C-reactive protein; s-CRP, serum CRP; $\mathrm{p}$-CRP, pleural CRP; Cl, confidence interval.

was correlated with overall survival by using a log-rank statistic, and found that p-CRP expression was significantly correlated with shorter overall survival $(p=0.006)$. The cumulative overall survival curves of patients were significantly split by p-CRP expression status (Fig. 4). The median overall survival of patients with low p-CRP expression was 11 months [95\% confidence interval (CI), 8.3-13.0]. How- ever, the median overall survival was reduced to 2.6 months (95\% CI, 1.5-4.7) in patients with high p-CRP expression (Table 2).

We then conducted multivariate analyses to assess the predictive value of $\mathrm{p}$-CRP expression for overall survival by adjusting other potentially prognostic factors. The results were consistent with unfavorable survival outcome in 
patients with high p-CRP expression. In a multivariate Cox regression analysis, a high p-CRP level was an independent prognostic factor significantly associated with poor survival $(p=0.0001)$. The relative risk of overall survival for patients with high p-CRP was 3.909 (95\% CI, 2.000-7.639), regardless of poor performance status [2.628 (95\% CI, 1.2545.508)]. The results from the Cox proportional hazards analysis are summarized in Table 3.

\section{DISCUSSION}

To the best of our knowledge, this is the first study on pleural effusions in which CRP levels were simultaneously investigated for their diagnostic and prognostic power of lung cancer with MPE. Our findings suggest that $\mathrm{p}$-CRP has a higher diagnostic accuracy than s-CRP for differentiating MPE from benign PE. In multivariate analysis, $\mathrm{p}$-CRP was revealed as a prognostic marker of lung cancer with MPE, together with performance status.

CRP synthesis in hepatocytes is mainly induced by interleukin (IL)-6, IL-1, and tumor necrosis factor $\alpha$. Although several studies have investigated CRP levels in various disease states, measurement of which is relatively inexpensive and easy to quantify in clinical practice, a few studies have focused on its role in patients with pleural effusions. ${ }^{17,27,28} \mathrm{~A}$ positive correlation between $\mathrm{p}$ - and s-CRP levels was demonstrated in the present study, suggesting that p-CRP may result from leakage of s-CRP via inflamed pleura. Further investigation is required to elucidate the exact mechanism. Botana-Rial, et al. ${ }^{29}$ reported that the diagnostic accuracies of $\mathrm{p}$ - and s-CRP for differentiating MPE from benign PE were 0.752 and 0.667 , respectively, as indicated by the area under the ROC curve. In agreement with these results, we demonstrated in the present study that the diagnostic accuracy of p-CRP for distinguishing lung cancer with MPE from benign PE was 0.86 , superior to that of s-CRP (0.77).

The reasons for CRP elevation in cancer patients are not completely understood. One possible explanation is that, due to cytokine production by tumor tissue, elevated CRP values may indicate a higher tumor burden. ${ }^{30} \mathrm{Scott}$, et al. ${ }^{31}$ reported a catabolic effect of acute-phase proteins like CRP on metabolism, and this is associated with an increase in resting energy expenditure and loss of lean tissue in patients with lung cancer, key factors in determining cancer survival. Another reason for elevated CRP may be a cancer-related infection, particularly a post-stenotic pulmonary infection in the case of lung tumors. It is well known that pneumonia may be the first sign that marks lung cancer. ${ }^{32}$

Multiple risk factors have been identified in advanced NSCLC that are able to discriminate patient groups with a significant difference in survival. ${ }^{33}$ However, only a few studies have analyzed CRP as a prognostic factor in advanced NSCLC. Moreover, it has been studied in heterogeneous groups of patients without taking treatment into consideration. ${ }^{34,35}$ To our best knowledge, this is the first study analyzing the prognostic value of p-CRP in lung cancer with MPE. In this study, we found by univariate analysis that $\mathrm{p}$ CRP levels $\geq 25 \mathrm{mg} / \mathrm{L}$ and old age were independent predictors of survival. Old age, found to be a factor in univariate survival analysis, was no longer significant in multivariate analysis. Both high p-CRP levels and poor performance status remained associated independently with survival in multivariate analysis. There were no significant differences in $\mathrm{WBC}$ and the frequency of bacterial culture growth in PE and sputum samples between high and low p-CRP patients. These results suggest that infection is not the main stimulus to the increased CRP.

The main limitation of the present study is that it is a retrospective study with comparatively small sample size. In spite of relatively high values of statistical significance obtained, further research with a larger group of patients is warranted. Further research is also required to identify other sensitive biological markers in PE, in order to define the best combination for marker analysis. Another limitation is that subjects in benign PE were either parapneumonic or tu-

Table 3. Multivariate Cox Proportional Hazards Analysis for Overall Survival in Lung Cancer with MPE

\begin{tabular}{llll}
\hline Parameters & Unfavorable & HR $(95 \% \mathrm{CI})$ & $p$ value \\
\hline Age & $>65$ & $1.899(0.957-3.765)$ & NS \\
Sex & Male & $1.472(0.625-3.466)$ & NS \\
Performance status & $3-4$ & $2.628(1.254-5.508)$ & 0.01 \\
Tumor type & Non-adenocarcinoma & $1.352(0.650-2.814)$ & NS \\
Clinical stage & Mlb & $1.113(0.614-2.018)$ & NS \\
P-CRP expression & High & $3.909(2.000-7.639)$ & 0.0001 \\
\hline
\end{tabular}

$\mathrm{HR}$, hazard ratio; $\mathrm{Cl}$, confidence interval; MPE, malignant pleural effusion. 
berculous effusion excluding other causes such as pulmonary thromboembolism, connective tissue diseases.

In conclusion, the results of current study indicate that diagnostic value of $\mathrm{p}-\mathrm{CRP}$ is superior to that of s-CRP in lung cancer patients with MPE, and that the presence of elevated p-CRP levels predicts poor outcome.

\section{ACKNOWLEDGEMENTS}

This study was supported by a grant from Institute of Wonkwang Medical Science.

\section{REFERENCES}

1. Memon A, Zawadzki ZA. Malignant effusions: diagnostic evaluation and therapeutic strategy. Curr Probl Cancer 1981;5:1-30.

2. Postmus PE, Brambilla E, Chansky K, Crowley J, Goldstraw P, Patz EF Jr, et al. The IASLC Lung Cancer Staging Project: proposals for revision of the $\mathrm{M}$ descriptors in the forthcoming (seventh) edition of the TNM classification of lung cancer. J Thorac Oncol 2007;2:686-93.

3. Fiegl M, Massoner A, Steurer M, Grünewald K, Krugmann J, Hack $\mathrm{R}$, et al. Improving tumor cell detection in pleural effusions by interphase cytogenetics. Cytometry B Clin Cytom 2003;55:60-2.

4. Ferrer J, Villarino MA, Encabo G, Felip E, Bermejo B, Vilà S, et al. Diagnostic utility of CYFRA 21-1, carcinoembryonic antigen, CA 125, neuron specific enolase, and squamous cell antigen level determinations in the serum and pleural fluid of patients with pleural effusions. Cancer 1999;86:1488-95.

5. Miédougé M, Rouzaud P, Salama G, Pujazon MC, Vincent C, Mauduyt MA, et al. Evaluation of seven tumour markers in pleural fluid for the diagnosis of malignant effusions. Br J Cancer 1999;81:1059-65.

6. Gu P, Huang G, Chen Y, Zhu C, Yuan J, Sheng S. Diagnostic utility of pleural fluid carcinoembryonic antigen and CYFRA 21-1 in patients with pleural effusion: a systematic review and meta-analysis. J Clin Lab Anal 2007;21:398-405.

7. Kim HJ, Shin KC, Lee JW, Kim KJ, Hong YH, Chung JH, et al. TNF-alpha in the pleural fluid for the differential diagnosis of tuberculous and malignant effusion. Tuberc Respir Dis 2005;59: 625-30.

8. Liang QL, Shi HZ, Qin XJ, Liang XD, Jiang J, Yang HB. Diagnostic accuracy of tumour markers for malignant pleural effusion: a meta-analysis. Thorax 2008;63:35-41.

9. Duffy MJ. Role of tumor markers in patients with solid cancers: a critical review. Eur J Intern Med 2007;18:175-84.

10. Coussens LM, Werb Z. Inflammation and cancer. Nature 2002; 420:860-7.

11. Mantovani A, Allavena P, Sica A, Balkwill F. Cancer-related inflammation. Nature 2008;454:436-44.

12. Chiang AC, Massagué J. Molecular basis of metastasis. N Engl J Med 2008;359:2814-23.

13. Mahmoud FA, Rivera NI. The role of C-reactive protein as a prognostic indicator in advanced cancer. Curr Oncol Rep 2002;4:250-5.
14. Pepys MB, Hirschfield GM. C-reactive protein: a critical update. J Clin Invest 2003;111:1805-12.

15. Korppi M, Heiskanen-Kosma T, Leinonen M. White blood cells, C-reactive protein and erythrocyte sedimentation rate in pneumococcal pneumonia in children. Eur Respir J 1997;10:1125-9.

16. Smith RP, Lipworth BJ. C-reactive protein in simple communityacquired pneumonia. Chest 1995;107:1028-31.

17. Castaño Vidriales JL, Amores Antequera C. Use of pleural fluid C-reactive protein in laboratory diagnosis of pleural effusions. Eur J Med 1992;1:201-7.

18. Yilmaz Turay U, Yildirim Z, Türköz Y, Biber C, Erdoğan Y, Keyf $\mathrm{AI}$, et al. Use of pleural fluid C-reactive protein in diagnosis of pleural effusions. Respir Med 2000;94:432-5.

19. Hara M, Matsuzaki Y, Shimuzu T, Tomita M, Ayabe T, Enomoto $\mathrm{Y}$, et al. Preoperative serum C-reactive protein level in non-small cell lung cancer. Anticancer Res 2007;27:3001-4.

20. Pelliniemi TT, Irjala K, Mattila K, Pulkki K, Rajamäki A, Tienhaara $\mathrm{A}$, et al. Immunoreactive interleukin- 6 and acute phase proteins as prognostic factors in multiple myeloma. Finnish Leukemia Group. Blood 1995;85:765-71.

21. Jabs WJ, Busse M, Krüger S, Jocham D, Steinhoff J, Doehn C. Expression of C-reactive protein by renal cell carcinomas and unaffected surrounding renal tissue. Kidney Int 2005;68:2103-10.

22. Nozoe T, Matsumata T, Kitamura M, Sugimachi K. Significance of preoperative elevation of serum C-reactive protein as an indicator for prognosis in colorectal cancer. Am J Surg 1998;176:335-8.

23. Hefler LA, Concin N, Hofstetter G, Marth C, Mustea A, Sehouli J, et al. Serum C-reactive protein as independent prognostic variable in patients with ovarian cancer. Clin Cancer Res 2008;14:710-4.

24. Hashimoto K, Ikeda Y, Korenaga D, Tanoue K, Hamatake M, Kawasaki $\mathrm{K}$, et al. The impact of preoperative serum $\mathrm{C}$-reactive protein on the prognosis of patients with hepatocellular carcinoma. Cancer 2005;103:1856-64.

25. Light RW. Diagnostic principles in pleural disease. Eur Respir J 1997;10:476-81.

26. Papageorgiou E, Kostikas K, Kiropoulos T, Karetsi E, Mpatavanis G, Gourgoulianis KI. Increased oxidative stress in exudative pleural effusions: a new marker for the differentiation between exudates and transudates? Chest 2005;128:3291-7.

27. Chierakul N, Kanitsap A, Chaiprasert A, Viriyataveekul R. A simple C-reactive protein measurement for the differentiation between tuberculous and malignant pleural effusion. Respirology 2004;9: 66-9.

28. Kim DY, Lee YS, Ahn S, Chun YH, Lim KS. The usefulness of procalcitonin and $\mathrm{C}$-reactive protein as early diagnostic markers of bacteremia in cancer patients with febrile neutropenia. Cancer Res Treat 2011;43:176-80.

29. Botana-Rial M, Casado-Rey P, Leiro-Fernández V, Andrade-Olivié M, Represas-Represas C, Fernández-Villar A. Validity of procalcitonin and $\mathrm{C}$-reactive protein measurement when differentiating between benign and malignant pleural effusion. Clin Lab 2011;57:373-8.

30. Heikkilä K, Ebrahim S, Lawlor DA. A systematic review of the association between circulating concentrations of $\mathrm{C}$ reactive protein and cancer. J Epidemiol Community Health 2007;61:824-33.

31. Scott HR, McMillan DC, Forrest LM, Brown DJ, McArdle CS, Milroy R. The systemic inflammatory response, weight loss, performance status and survival in patients with inoperable non-small cell lung cancer. Br J Cancer 2002;87:264-7.

32. Søyseth V, Benth JS, Stavem K. The association between hospi- 
talisation for pneumonia and the diagnosis of lung cancer. Lung Cancer 2007;57:152-8.

33. Brundage MD, Davies D, Mackillop WJ. Prognostic factors in non-small cell lung cancer: a decade of progress. Chest 2002;122: 1037-57.

34. Forrest LM, McMillan DC, McArdle CS, Angerson WJ, Dunlop DJ. Evaluation of cumulative prognostic scores based on the sys- temic inflammatory response in patients with inoperable nonsmall-cell lung cancer. Br J Cancer 2003;89:1028-30.

35. O'Dowd C, McRae LA, McMillan DC, Kirk A, Milroy R. Elevated preoperative C-reactive protein predicts poor cancer specific survival in patients undergoing resection for non-small cell lung cancer. J Thorac Oncol 2010;5:988-92. 